\section{Diclofenac hepatitis}

\author{
P Purcell, D Henry, G Melville
}

Non-steroidal anti-inflammatory drugs are used extensively in Australia, and in recent years diclofenac has maintained a consistently high market share. During this period the Adverse Drug Reactions Advisory Committee has received a larger number of reports of hepatic reactions to diclofenac than to any other drug. In this paper we review these reports with particular attention to the strength of the association between diclofenac use and liver injury, the clinical and biochemical features of the patients, and the question of whether there are any predictors of the severity of the reactions and the duration of the recovery period.

\section{Patients and methods}

We reviewed all cases of hepatic dysfunction associated with the use of diclofenac reported to Adverse Drug Reactions Advisory Committee between March 1981 (the date marketing started in Australia) and April 1989. The committee collects detailed information on all serious adverse drug reactions identified through the national voluntary reporting scheme. This information includes the dates of starting and stopping all drugs being used by the patient and details of dosage, age, sex, and weight of the patient. Through contact with the reporter an attempt is made to collect all relevant laboratory data. In the case of hepatic reactions this includes liver function tests, serological tests for hepatitis $A$ and $B$, and, where relevant, the results of imaging procedures, the histology of any liver biopsies, and necropsy findings. Each report is reviewed by the committee, which comprises six specialist physicians, including a gastroenterologist. In this paper we review those cases for which, in the opinion of the committee, diclofenac was the sole suspected drug used by the patient before the development of the illness.

To facilitiate comparisons between individuals and across laboratories, laboratory data for total bilirubin, aspartate transaminase, alanine transaminase, serum alkaline phosphatase, and $\gamma$ glutamyltransferase were expressed as multiples (deviate ratios) of the upper limit of the normal range for the laboratory. For this study 'recovery' was defined as spontaneous return to 'normal' of all of the following four parameters: bilirubin, aspartate transaminase, alanine transaminase, and serum alkaline phosphatase. Values were regarded as returning to normal if the deviate ratio was less than 2 .

\section{STATISTICAL ANALYSES}

In order to perform statistical analyses serum transaminase levels from individuals who had repeated testing were fitted to the following exponential model. abnormal liver function tests of 2 to $4 \%$ has been with the comparison drugs. ${ }^{2}$ Most of these reactions, however, were asymptomatic and, as with other members of this class of drugs, reports of clinically important reactions have described only a few cases. . $^{3-11}$ 
TABLE I Details of fatal cases

\begin{tabular}{|c|c|c|c|c|c|c|}
\hline $\begin{array}{l}\text { Sex/ } \\
\text { age (years) }\end{array}$ & $\begin{array}{l}\text { Duration of } \\
\text { treatment } \\
\text { (days) }\end{array}$ & $\begin{array}{l}\text { Daily } \\
\text { dose } \\
(m g)\end{array}$ & $\begin{array}{l}\text { Underlying } \\
\text { diseases }\end{array}$ & $\begin{array}{l}\text { Clinical } \\
\text { features }\end{array}$ & Laboratory data & Comments \\
\hline$M / 80$ & 30 & 150 & Arthritis & $\begin{array}{l}\text { Jaundice: pale stools and dark } \\
\text { urine; encephalopathy; } \\
\text { gastrointestinal } \\
\text { haemorrhage }\end{array}$ & $\begin{array}{l}\text { Peak AST } 30.9 \text { DR; albumin } 26 \mathrm{~g} / \mathrm{l}(\mathrm{NR} \\
\text { 39-48); prothrombin ratio } 3 \cdot 4(0 \cdot 8- \\
1 \cdot 2) \text {; serology hepatitis A\&B negative; } \\
\text { histology: cirrhosis with piecemeal } \\
\text { necrosis }\end{array}$ & Chronic heavy alcohol intake \\
\hline $\mathrm{F} / 70$ & 5 & 150 & $\begin{array}{l}\text { Degenerative } \\
\text { joint disease }\end{array}$ & Hypotension, asterixis & $\begin{array}{l}\text { Peak AST } 80 \cdot 7 \text { DR; albumin } 23 \mathrm{~g} / \mathrm{l} \text { (NR } \\
\text { 35-45) }\end{array}$ & $\begin{array}{l}\text { Cardiac arrest two days after stopping } \\
\text { diclofenac; normal liver function tests } \\
\text { before diclofenac; no necropsy; } \\
\text { multiple drugs suspected }\end{array}$ \\
\hline$F / 60$ & 109 & 150 & $\begin{array}{l}\text { Arthritis; } \\
\text { rheumatic } \\
\text { mitral valve } \\
\text { disease }\end{array}$ & $\begin{array}{l}\text { Nausea, deep jaundice, } \\
\text { encephalopathy, bruising, } \\
\text { no stigmata of chronic liver } \\
\text { disease }\end{array}$ & $\begin{array}{l}\text { Peak AST } 52 \cdot 8 \text { DR; peak ALT } 70.6 \text { DR; } \\
\text { prothrombin time } 60 \text { sec; albumin } \\
27 \text { g/l (NR 35-45); serology hepatitis } \\
\text { A\&B negative; ultrasound: no } \\
\text { evidence of biliary obstruction }\end{array}$ & $\begin{array}{l}\text { No report of alcohol intake; liver biopsy } \\
\text { not possible because of coagulopathy; } \\
\text { died four weeks after stopping } \\
\text { diclofenac; necropsy not done }\end{array}$ \\
\hline M/66 & 300 & $\begin{array}{l}\text { Not } \\
\text { known }\end{array}$ & Osteoarthritis & $\begin{array}{l}\text { Anorexia and nausea, dark } \\
\text { urine and pale stools; deeply } \\
\text { jaundiced; non-tender } \\
\text { hepatomegaly; no stigmata } \\
\text { of chronic liver disease }\end{array}$ & $\begin{array}{l}\text { Peak AST } 28 \cdot 7 \text { DR; albumin } 23 \mathrm{~g} / \mathrm{l} \\
\text { (NR 35-45); serology hepatitis A\&B } \\
\text { negative; ultrasound: gall bladder } \\
\text { stones but no biliary obstruction; } \\
\text { laparoscopy: ascites; histology: } \\
\text { subacute hepatic necrosis; very few } \\
\text { hepatocytes; round cell and } \\
\text { polymorphonuclear leucocyte } \\
\text { infiltration; pigment laden } \\
\text { macrophages }\end{array}$ & $\begin{array}{l}\text { Alcohol intake reported at } 125 \mathrm{~g} / \text { week; } \\
\text { died of subacute liver failure after } \\
\text { illness lasting } 10 \text { weeks }\end{array}$ \\
\hline
\end{tabular}

AST = aspartate transaminase ALT =alanine transaminase; $\mathrm{DR}=$ deviate ratio (see text) $\mathrm{NR}=$ normal range for laboratory.

$\mathrm{TA}=\mathrm{a} \cdot \mathrm{PTA} \mathrm{e}^{\mathrm{bt}}$ where

$\mathrm{TA}=$ circulating transaminase (expressed as a deviate ratio)

PTA = peak transaminase activity (expressed as a deviate ratio)

e $\quad=$ the base of natural logarithms

$\mathrm{t}=$ time since PTA and $\mathrm{a}$ and $\mathrm{b}$ are constants for the individual.

If the exponential model for the postpeak phase of recovery is valid, the area under the transaminase versus time curve can be calculated and the duration of the postpeak phase of recovery can be estimated by regression of log aspartate transaminase (or log alanine transaminase) against time. The mean recovery phase transaminase activity can then be calculated from the ratio of the total area under the transaminase versus time curve during the recovery phase to the total duration of the recovery phase.

In cases where accurate information on daily dose and duration of administration of diclofenac enabled calculation of the total dose taken, these estimates of the cumulative dose were used as the independent variable in regression analysis against peak and mean transaminase activities. Because of the skewed frequency distribution of the data, log transformations were used. The coefficient of determination, the coefficient of regression, and the $\mathrm{F}$ statistic were calculated

TABLE II Exclusions (nine)

\begin{tabular}{ll}
\hline $\begin{array}{l}\text { Other cause } \\
\text { Positive serology for hepatitis B }\end{array}$ & 1 \\
$\begin{array}{l}\text { Outcome unknown } \\
\text { Recovery after treatment with steroids }\end{array}$ & 1 \\
$\begin{array}{l}\text { Temporal relation unclear: } \\
\text { Recovery 12 days before withdrawal of diclofenac }\end{array}$ & 1 \\
$\begin{array}{l}\text { Significant ( }>50 \% \text { drop in alanine transaminase) partial } \\
\text { recovery documented 10 weeks before withdrawal of } \\
\text { diclofenac treatment 'chronic active hepatitis' - biopsy }\end{array}$ & 1 \\
$\begin{array}{l}\text { Partial recovery followed by spontaneous deterioration at } \\
\text { 10 weeks after withdrawal of diclofenac }\end{array}$ & 1 \\
$\begin{array}{l}\text { Spontaneously developed abnormal liver function tests } \\
\text { before a planned rechallenge }\end{array}$ & 1 \\
$\begin{array}{l}\text { Abnormal liver function tests on first day of diclofenac } \\
\text { exposure }\end{array}$ & 1 \\
$\begin{array}{l}\text { Diclofenac withdrawn } 36 \text { days before first recorded } \\
\text { abnormal liver function test }\end{array}$ & 1 \\
\hline
\end{tabular}

for maximum and mean aspartate transaminase maximum and mean alanine transaminase, maximum $\gamma$ glutamyltransferase, and maximum bilirubin against total dose.

\section{Results}

Between March 1981 and April 1989 the committee received 82 reports of suspected hepatotoxicity associated with the use of diclofenac sodium (Voltaren R, Ciba-Geigy). The sustained released version of this drug is not marketed in Australia.

\section{FATAL CASES}

In all, four patients who had developed hepatocellular damage while taking diclofenac were reported to have died. Table I gives their details. In one, heavy alcohol consumption seemed the most likely explanation and he was excluded from further consideration. The second patient, a 70 year old woman had been taking multiple drugs. The relation of diclofenac to her liver damage was unclear, and although she had some features of liver failure, her death was due to cardiac arrest two days after withdrawal of diclofenac. The third patient had mitral valve disease. Her level of cardiac function and her alcohol intake were not reported. She died of liver failure but a liver biopsy could not be performed and permission for necropsy was refused. The role of diclofenac in this case remains unclear. In the fourth case no causal factor other than diclofenac was identified. The patient died of liver failure 10 weeks after the onset of the illness and necrospy showed features of subactue hepatic necrosis. This last case resembles previously reported cases of fatal liver damage during diclofenac treatment. ${ }^{67910}$

VALIDATION OF NON-FATAL CASES

Of the 78 surviving cases of hepatocellular damage the committee assessed diclofenac sodium was the sole suspected drug in 55 . Results 
of liver function tests performed around the time of the diagnosis were reported, or subsequently obtained, for 45 of these patients, in 35 of whom the results of serial liver function tests (at least two parameters on at least three different days) were obtained. A further nine cases were excluded from more detailed analysis for the reasons summarised in Table II. It will be appreciated from Table II that a causal role for diclofenac cannot be ruled out completely in these cases.

There remained 26 cases who met the following criteria: diclofenac was the sole suspected drug; the patient recovered after drug use stopped; no other treatment was given for the reaction; no other probable cause of hepatic dysfunction was found; the results of liver function tests were

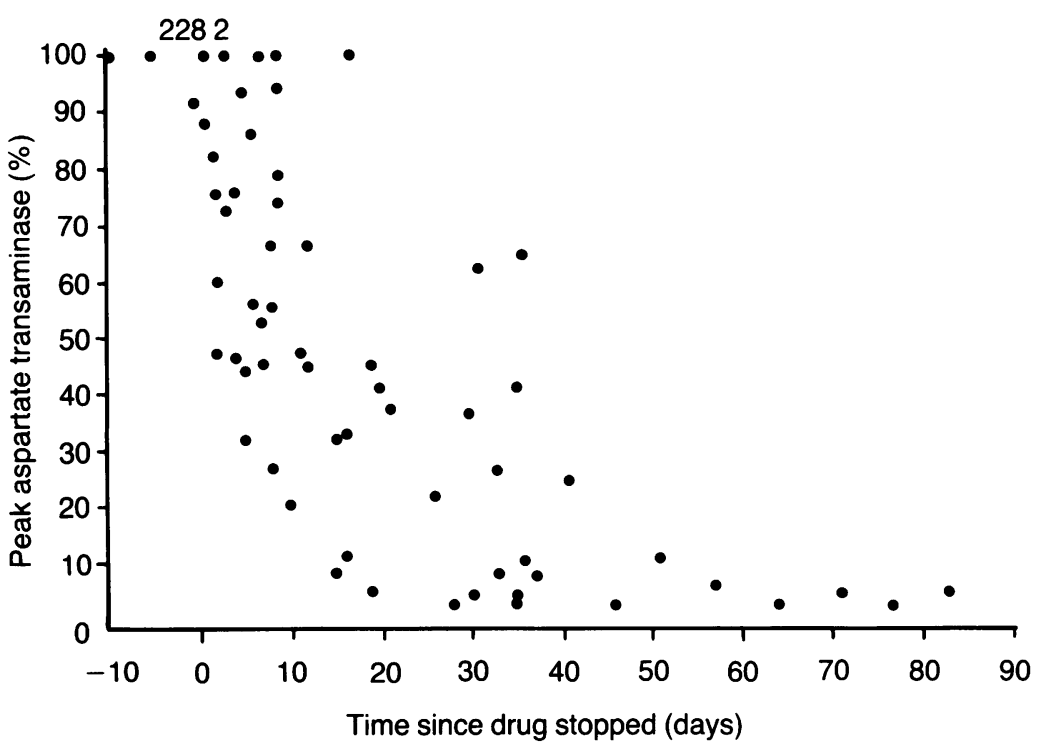

Figure 1: Serum aspartate transaminase levels after withdrawal of diclofenac treatment in 21 subjects with diclofenac associated hepatocellular damage. Levels have been plotted as per cent of peak levels for individuals and the figure includes the first recorded normal value for each individual. When levels (expressed as deviate ratios) were regressed on time the data were fitted best by an exponential function: (log aspartate transaminase $\mathrm{v}$ time): $r^{2}=0.722$, slope -0.05 , $p<0.0001$.

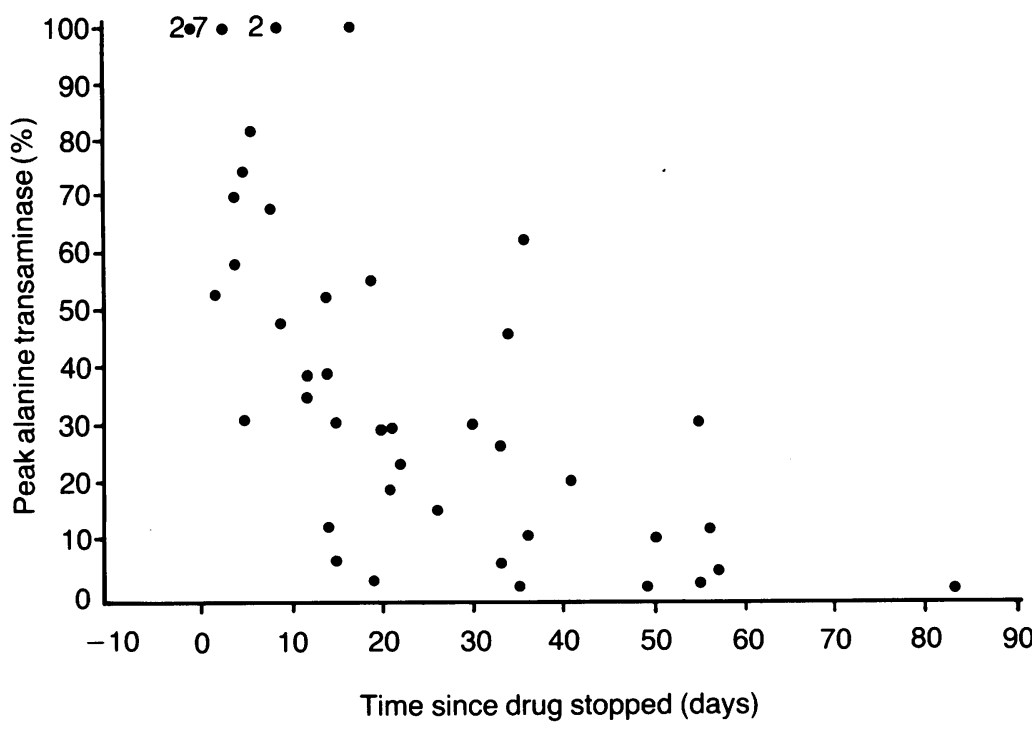

Figure 2: Serum alanine transaminase levels after withdrawal of diclofenac treatment in 15 subjects with diclofenac associated hepatocellular damage. Levels have been plotted as per cent of peak levels for individuals and the figure includes the first recorded normal value for each individual. When levels (expressed as deviate ratios) were regressed on time the data were fitted best by an exponential function: (log alanine transaminase v time): $r^{2}=0 \cdot 628$, slope -0.053 , $p<0.0001$.
TABLE III Clinical features

\begin{tabular}{lr}
\hline Jaundice & 15 \\
Hepatomegaly & 6 \\
Anorexia & 6 \\
Nausea & 6 \\
Pruritus & 4 \\
Hepatic pain & 4 \\
Asymptomatic & 4 \\
Malaise & 4 \\
Symptoms not specified & 3 \\
Vomiting & 2 \\
Splenomegaly & 1 \\
(associated with hepatomegaly) & \\
\hline
\end{tabular}

^ Most patients presented with more than one symptom or sign.

available on at least three occasions, at least one of which was in the recovery phase. Serology for hepatitis A and B was negative in 15 who were tested. A few reports included negative results of other serological tests - for example, EpsteinBarr virus and cytomegalovirus. Ultrasound or computed tomography had been considered necessary to exclude obstruction of the biliary system in another seven cases and the results were negative. Only one case had had a liver biopsy. The report of the histology of the biopsy specimen favoured drug induced hepatitis.

\section{Clinical features}

The average age of cases was 64 years (range 3784 years). Nineteen $(70 \%)$ were women. The main clinical features of the cases are summarised in Table III. These included some degree of jaundice (total bilirubin deviate ratio $>2$ ) in half the cases, hepatomegaly (sometimes painful), anorexia, and nausea. Less commonly, itch, malaise, or vomiting occurred. One quarter of patients seemed to be asymptomatic. In general, extrahepatic phenomena suggestive of hypersensitivity such as skin rashes, blood dyscrasias, eosinophilia, lymphadenopathy, and immunological abnormalities were not reported. Two reports, however, documented mild thrombocytopenia. Splenomegaly (in conjunction with hepatomegaly) was reported in one case.

In 18 of 21 reports which provided accurate information on the duration of diclofenac treatment before the onset of liver damage, onset was within the first six months. For the whole group the median duration of exposure was 76 days (range 6-417 days). The median cumulative dose taken by 18 patients for whom accurate data were available was $8 \cdot 7 \mathrm{~g}(1 \cdot 4-63 \cdot 5 \mathrm{~g})$.

\section{Biochemical features}

The dominant feature of the biochemical reaction was raised circulating transaminase activity, which was accompanied in most cases by lesser disturbances of serum alkaline phosphatase, $\gamma$ glutamyltransferase, and bilirubin concentrations (Table IV). A spectrum of severity was evident, ranging from minor disturbances to rises of fortyfold in transaminase activity.

From scrutinising individual reports it seemed that circulating transaminase activity occasionally continued to rise for some days after withdrawal of diclofenac but more commonly fell promptly. An impression of the pattern of recovery of liver function tests after discontinuation of diclofenac can be gained from the 
TABLE IV Summary of variables

\begin{tabular}{|c|c|c|c|c|}
\hline Variable & No & Mean & Median & Maximum \\
\hline Aspartate transaminase: maximum deviate ratio & 21 & $13 \cdot 0$ & $11 \cdot 3$ & $34 \cdot 4$ \\
\hline Alanine transaminase: maximum deviate ratio & 15 & $16 \cdot 0$ & 10.5 & $40 \cdot 5$ \\
\hline Serum alkaline phosphatase: maximum deviate ratio & 25 & $2 \cdot 3$ & $2 \cdot 2$ & $4 \cdot 8$ \\
\hline$\gamma$ glutamyltransferase: maximum deviate ratio & 26 & $7 \cdot 2$ & $6 \cdot 5$ & $20 \cdot 8$ \\
\hline Bilirubin: maximum deviate ratio & 26 & $3 \cdot 6$ & $2 \cdot 8$ & $14 \cdot 0$ \\
\hline Aspartate transaminase: recovery (days) & 21 & $40 \cdot 5$ & $43 \cdot 1$ & $70 \cdot 8$ \\
\hline Alanine transaminase: recovery (days) & 15 & $39 \cdot 5$ & $36 \cdot 6$ & $79 \cdot 1$ \\
\hline Aspartate transaminase: area under the curve & 21 & $185 \cdot 8$ & $162 \cdot 7$ & $647 \cdot 1$ \\
\hline Alanine transaminase: area under the curve & 15 & $245 \cdot 7$ & $245 \cdot 3$ & $900 \cdot 4$ \\
\hline Aspartate transaminase: mean & 21 & $4 \cdot 5$ & $4 \cdot 2$ & $9 \cdot 4$ \\
\hline Alanine transaminase: mean & 15 & $5 \cdot 6$ & $5 \cdot 4$ & $11 \cdot 7$ \\
\hline
\end{tabular}

grouped data in Figures 1 and 2. Serial aspartate transaminase and alanine transaminase levels from individual patients have been plotted as percentages of maximum observed values against time. The impression is that the fall in transaminase levels was exponential from around

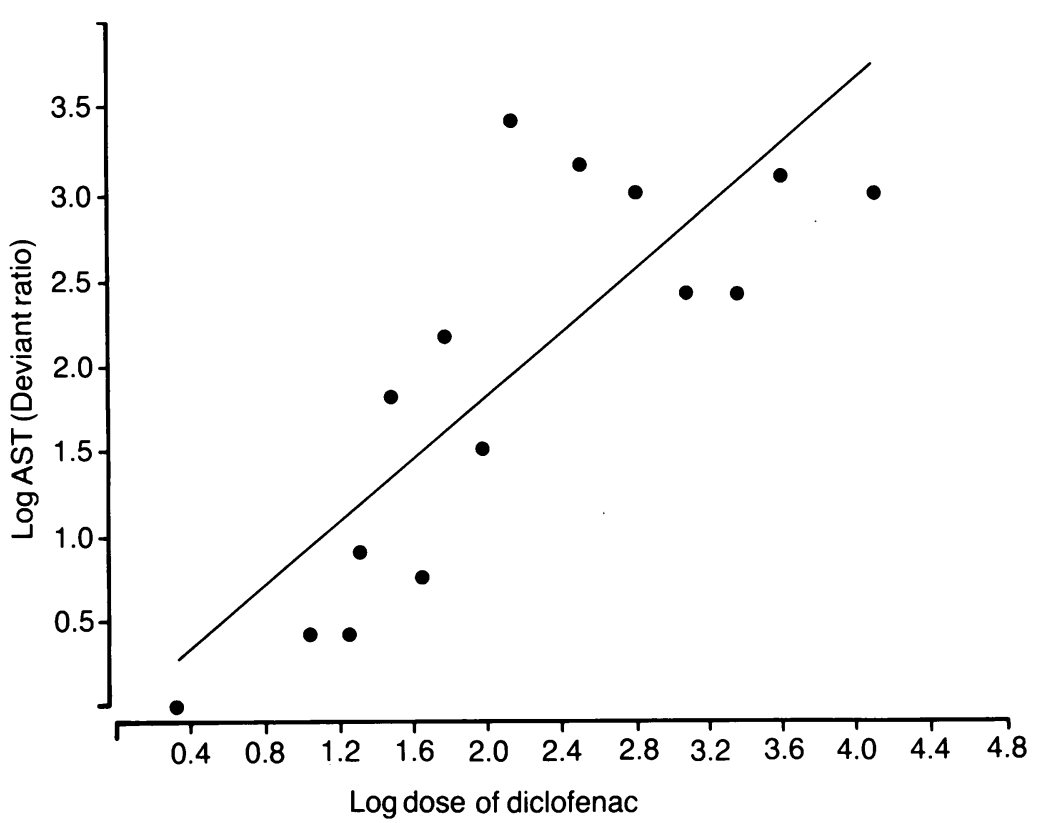

Figure 3: Relation between diclofenac dose and severity of liver damage as reflected by peak aspartate transaminase (AST) levels (expressed as deviate ratios). There was a significant relation between log dose and $\log D R_{A S T}: r^{2}=0.68$, slope $0.91, p=0.0001$.

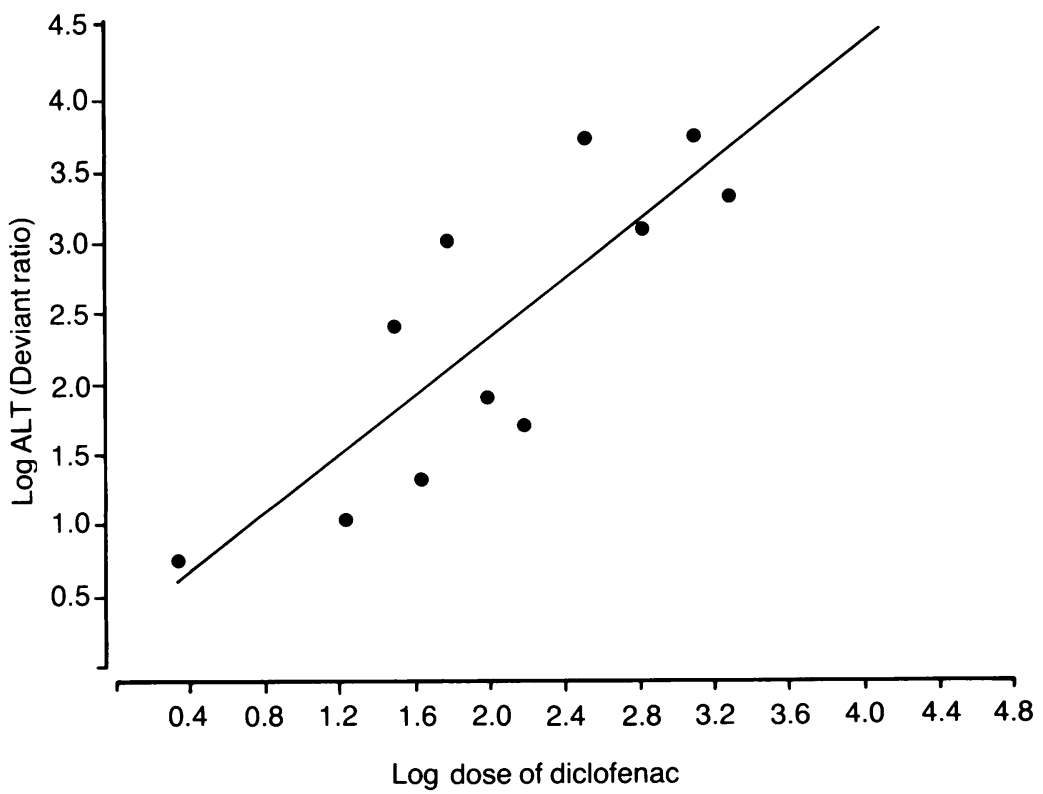

Figure 4: Relation between diclofenac dose and severity of liver damage as reflected by peak alanine transaminase ( $A L T$ ) levels (expressed as deviate ratios). There was a significant relation between log dose and $\log D R_{A L T}: r^{2}=0 \cdot 71$, slope $1 \cdot 04, p=0 \cdot 001$. the time diclofenac treatment was withdrawn. When regression analysis was performed the data were fitted well by exponential functions (for regression data see Figs 1 and 2). The slopes of the two exponents are equivalent to postpeak half lives for aspartate and alanine transaminases of $13 \cdot 7$ and $13 \cdot 2$ days respectively.

\section{RELATION BETWEEN CUMULATIVE DOSE AND} SEVERITY OF LIVER DAMAGE

In cases where there were complete data, the relation between cumulative dose of diclofenac assumed to have been taken and the severity of the hepatic injury was examined by regressing the log peak aspartate transaminase and alanine transaminase values (expressed as deviate ratios) on log cumulative dose. As the data in Figures 3 and 4 show, there was a significant correlation between cumulative dose and effect with both of these parameters. This exercise was repeated by regressing mean values for both on $\log$ cumulative dose, and once again significant correlations were found: mean aspartate transaminase $r^{2}=0.49, p=0.003$; mean alanine transaminase $r^{2}=0.59, p=0.006$.

Correlations between other measures of diclofenac exposure and the severity of liver damage were not high as the following statistics show. Regression of log peak aspartate transaminase and alanine transaminase on duration of treatment $\mathrm{r}^{2}=0.18, \mathrm{p}=0.07$ and $\mathrm{r}^{2}=0.22$, $p=0 \cdot 11$, respectively; regression of $\log$ peak aspartate transaminase and alanine transaminase on daily dose: $r^{2}=0.13, p=0.15$ and $r^{2}=0.08$, $\mathrm{p}=\mathbf{0 . 3 4}$ respectively. Attempts to correlate $\log$ cumulative dose with other measures of liver injury were also relatively unrewarding. Log serum alkaline phosphatase $r^{2}=0.094, p=0.23$; $\log \gamma$ glutamyltransferase $r^{2}=0.350, p=0.01 ; \log$ bilirubin $r^{2}=0 \cdot 29, p=0 \cdot 01$.

\section{Discussion}

To date this is the largest published series of cases of hepatocellular damage associated with use of diclofenac. There were several notable features. Firstly, onset was often delayed several weeks after the start of diclofenac treatment. The biochemical abnormalities were predominantly those of an acute hepatitic reaction with pronounced rises in transaminase levels. The usual features of drug hypersensitivity reactions such as rash and eosinophilia were not reported. It should be noted that these features have been reported in several cases, although a recent case series reported from Oxford emphasised the absence of features of hypersensitivity in five cases of diclofenac hepatitis. ${ }^{3-68911}$ In the Australian cases recovery was generally rapid after diclofenac was stopped. Unexpectedly, there was an apparent relation between the cumulative dose of diclofenac reported to have been taken and certain biochemical measures of the severity of the hepatic injury. These latter observations are important as they increase the likelihood of causal relations in a series of cases that generally were not extensively investigated.

Most of the reports of diclofenac associated hepatitis were made by family practitioners and 
general physicians. Many reports were sketchy and even after detailed follow up by the secretariat incomplete information was available for some cases on, for instance, alcohol intake, serological testing for viral hepatitis, immunological tests, and biopsy results. It is important to understand that some investigations, particularly biopsy, were probably regarded by doctors as unnecessary because of the acute nature of the reaction and the relatively rapid response to withdrawal of the drug. Liver histology was available for only one patient in this series of validated cases. The features were those of acute hepatitis, similar to those reported recently for a series of cases from Oxford."

From the pattern of abnormality reported in this series it seems that the most important differential diagnosis of diclofenac hepatitis is hepatitis C. Because of the extent of use of nonsteroidal anti-inflammatory drugs, particularly diclofenac, spurious associations are likely. This series of cases was reported before the availability of a serological test for hepatitis C. In future this test will be an important part of the investigation of possible drug induced hepatitis.

Although we have described a relatively large series of cases of diclofenac associated hepatitis, the number has to be viewed in the context of the overall use of this drug by the Australian community. During the period covered by this report approximately 15 million packs (50 doses) of diclofenac were sold (data provided by CibaGeigy, Australia). In total, 58 cases of hepatocellular damage where diclofenac was the sole suspected drug were reported, giving a crude rate of 3.8 reported cases/million prescriptions. Only 26 of these cases met our criteria for further study, yielding a rate of 1.8 'validated' cases/ million prescriptions. Only limited importance can be attached to these figures as the reporting of spurious associations and a tendency to underreporting of adverse drug reactions in general can introduce large errors when attempts are made to derive incidence figures from voluntary report data. It can be assumed, however, that clinically important liver injury is a relatively rare occurrence during treatment with diclofenac. Furthermore, in most cases the illness was mild and resolved promptly after withdrawal of the drug. Of four deaths reported to us, one was probably due to alcohol and unrelated to the drug. In two other cases assessment of cause could not be made because of incomplete information. In the fourth case diclofenac was considered to be the probable cause of death from massive hepatic necrosis. This latter case was similar to fatalities from diclofenac associated liver failure previously reported..$^{67910}$

At a meeting of the arthritis drugs advisory committee of the United States Food and Drug
Administration in May 1988 the manufacturer of diclofenac, Ciba-Geigy, reported 408 cases of hepatic adverse reactions to the drug, of which 15 were reported to have died of liver failure during the 14 years that the product had been available. ${ }^{12}$ Comparative data are not available for other non-steroidal anti-inflammatory drugs. We are unable therefore to say whether serious liver injury is a more common complication with diclofenac than with other non-steroidal antiinflammatory drugs. This highlights the need for more openness on the part of pharmaceutical manufacturers, and properly controlled pharmacoepidemiological studies of the various serious adverse effects of these commonly used drugs.

The most surprising finding in this series was the correlation between the total dose of diclofenac reported to have been taken and the biochemical measure of the severity of the hepatic lesion. The explanation is not clear, but in view of the absence of the typical features of drug hypersensitivity in the Australian cases the finding may indicate that for some patients this reaction is a direct toxic effect of the drug. This possibility has been suggested previously. ${ }^{311}$ Impaired metabolic clearance resulting in accumulation of diclofenac or a metabolite, or formation of a toxic reactive metabolite, could be an explanation, and such a trait could be genetically determined. As diclofenac is rapidly eliminated and the onset of hepatotoxicity was often delayed we favour accumulation of a metabolite as the explanation for this observation.

A subset of these data were originally reported by Dr John McEwen and Dr Joy Downton at the 10th meeting of the International Union of Pharmacology in Sydney, August 23-28, 1987. Some of the cases were also described in the Australian Adverse Drug Reactions Bulletin in June 1986.

1 Paulus HE. FDA Arthritis Advisory Committee Meeting. Arthritis Rheum 1982; 25: 1124-5.

2 Anonymous. Details of U.S. Voltaren labelling, Scrip 1988; 1334: 22.

3 Dunk AA, Walt RP, Jenkins WJ, Sherlock S. Diclofenac hepatitis. BMF 1982; 284: 1605-6.

4 Babany G, Pessayre D, Benhamou J-P. Hépatite au diclofénac. Gastroenterol Clin Biol 1983; 7: 316 .

5 Deshayes P, Leloet X, Bercoff E, Fouin-Fortunet H. Hépatite au diclofénac. Presse Med 1984; 13: 1847.

6 Lascar G, Grippon P, Lévy V-G. Hépatite aiguë mortelle au cours d'un traitimant par le dicloféncac. Gastroenterol Clin Biol 1984; 8: 881-2.

7 Babany G, Bernuau J, Danan G, Rueff B, et al. Hépatite fulminante chez une femme prenant de la glafénine et du diclofénac. Gastroenterol Clin Bio 1985; 9: 185 .

8 Schapira D, Bassan L, Nahir AM, Scharf Y. Diclofenacinduced hepatotoxicity. Postgrad Med f 1986; 62: 63-5.

9 Breen EG, McNicholl J, Cosgrove E, McCabe J, Stevens FM. Fatal hepatitis associated with diclofenac. Gut 1986; 27 1390-3.

10 Snijder RJ, Dinant HJ, Stricker B.H.CH. Dodelijke leverbeschadiging tijdens gebruik van diclofenac. Ned leverbeschadiging tijdens gebruik van
Tijdschr Geneeskd 1987; 131: 2088-90.

11 Iveson TJ, Ryley NG, Kelly PMA, Trowell JM, McGee O'D Chapman RWG. Diclofenac associated hepatitis. $\mathcal{F}$ Hepatol 1990; 10: 85-90.

12 Anonymous. Voltaren "approvable" in the U.S. FDA caution on NSAI labelling. Scrip 1988; 1311: 22-3. 